\title{
Social and Behavioral Impacts of COVID-19 on People Living with HIV: Review of the First Year of Research
}

\author{
Seth C. Kalichman ${ }^{1} \cdot$ Renee El-Krab ${ }^{1}$ \\ Accepted: 15 November 2021 / Published online: 26 November 2021 \\ (c) The Author(s), under exclusive licence to Springer Science+Business Media, LLC, part of Springer Nature 2021
}

\begin{abstract}
Purpose of the Review The SARS-CoV-2 (COVID-19) pandemic brought unprecedented social change with the most severe impacts on the most vulnerable populations, including people living with HIV (PLWH). This review examined findings from empirical studies of social and behavioral impacts of COVID-19 on PLWH in the first year of the pandemic.

Recent Findings Impacts of COVID-19 on PLWH fit within an HIV syndemics framework, with overlapping COVID-19 and HIV comorbid conditions concerning mental health and structural inequality. Early impacts of COVID-19 on social isolation, emotional distress, stigma, and substance use varied across studies with few consistent patterns. Structural inequalities, particularly impacts on food security and housing stability, were observed more consistently and globally.

Summary COVID-19 intersects with HIV infection along with multiple interlocking comorbidities that are best characterized and understood within a syndemics framework.
\end{abstract}

Keywords HIV-COVID-19 co-infection · Social impacts · Behavioral impacts · People living with HIV

\section{Introduction}

In the first quarter of 2020, the SARS-CoV-2 pandemic disrupted nearly every facet of human interaction worldwide, including efforts to conduct ongoing research. Recognizing the widespread impacts of SARS-CoV-2, the cause of COVID-19, virologists and public health researchers working on HIV infection quickly turned their attention to the structure, pathogenesis, and prevention of this new pathogen. For social and behavioral scientists working on HIV infection, the challenges posed by a novel life-threatening communicable disease were apparent and familiar [1,2]. For many researchers, ongoing studies that were focused on the health and behavior of people living with HIV (PLWH) were seen as opportunities to study the impacts of COVID19 on PLWH. Here, we review the social and behavioral

This article is part of the Topical Collection on The Global Epidemic

Seth C. Kalichman

seth.k@uconn.edu

1 Institute for Collaboration On Health Intervention and Policy, University of Connecticut, 2006 Hillside Road, Storrs, CT 06269, USA research concerning the impacts of COVID-19 on PLWH that reported data collected in the first year of the SARSCoV-2 pandemic.

COVID-19 complicates the clinical course of HIV infection and vice versa. Early observers reported that PLWH experienced more severe clinical outcomes from COVID19 compared to people not living with HIV [3]. In a review of 22 studies with 20,982,498 patients across Africa, Asia, Europe, and North America, Ssentongo et al. [4] found that PLWH were significantly more likely to develop COVID19 and had greater COVID-19 mortality than their HIVnegative counterparts. Greater severity and death rates from COVID-19 among PLWH have been confirmed [5, 6]. Factors such as immune suppression, chronic inflammation, and other underlying conditions associated with HIV infection likely account for greater COVID-19 severity in PLWH [3, 4]. Studies show that when HIV is fully suppressed, the clinical course of COVID-19 may be no different for people with HIV than it is for people who are HIV negative, with comorbid conditions complicating the protective benefits of viral suppression [7]. There is also evidence that antiretroviral therapies (ART) may offer some clinical benefit in COVID-19, although the evidence for these protective effects of ART are inconclusive [4, 8-10]. The potential for more severe COVID-19 clinical outcomes among PLWH 
brought a sense of urgency to understanding the social and behavioral impacts of COVID-19 on PLWH.

A substantial literature on the social and behavioral implications of COVID-19 for PLWH emerged within the first year of the SARSCoV-2 pandemic. Unlike the first years of the HIV pandemic which were met with relative indifference, the early weeks of COVID-19 were met with entire countries and industries mobilized to contain and prevent the spread of infection. In a review of rapidly conducted studies, commentaries, and editorials concerning the social impacts HIV-affected populations, Winwood et al. [11] examined research published through January 31, 2021. Taking a broad approach, the review identified several emerging trends in the early studies of COVID-19-HIV co-infection, including expansion of telehealth and impacts on mental health, food insecurity, social isolation, finances and sexual behavior. The clustering of multiple impacts around COVID-19 and their implications for PLWH indicated that COVID-19 could be considered a contributing condition and complication in the broader context of factors that influence HIV infection.

\section{COVID-19 and HIV Syndemics}

The COVID-19 and HIV pandemics intersect in the context of multiple overlapping comorbidities at the individual and structural levels. For example, type- 2 diabetes and metabolic syndrome significantly contribute to the severity of COVID19 , as well as contributing to the morbidity and mortality of HIV infection [12-14]. Several other health conditions that increase the risk for severe COVID-19 are prevalent in PLWH, including hypertension, obesity, and chronic pulmonary disease [15]. Furthermore, ART is associated with metabolic disruptions that can complicate the clinical course of type-2 diabetes and metabolic syndrome [16]. Stress, depression, and substance use, which are prevalent among PLWH, have immune-suppressive effects which may also complicate COVID-19 [17]. In addition, public health responses to slowing SARS-CoV-2 transmission center on social distancing, which may contribute to social isolation, raising particular concern for many PLWH who are already socially marginalized [18]. The potential for COVID-19's synergistic relationships with HIV infection and their multiple co-occurring conditions have brought some social and behavioral HIV researchers to conceptualize COVID19-HIV co-infection within a syndemics framework [19]. Defined as two or more epidemics that interact to synergistically facilitate greater disease burden [20], COVID-19 adds to the already multiple co-occurring conditions in HIV syndemics, including other infectious and non-infectious diseases, mental health conditions, emotional distress, and alcohol and other substance use [20]. A syndemics framework highlights how these conditions and others known to co-occur with HIV are exacerbated by COVID-19 [21].
Subclinical comorbidities such as urogenital inflammation, renal disease, metabolic syndrome, and others are also prevalent in PLWH and increase risks for severe COVID19 [1]. In addition, social isolation promoted by physical distancing and self-quarantine increases the risk for adverse drug use events driven by limited access to clean drug use supplies and unaccompanied overdose [22]. Because of the synergistic nature of these comorbidities, changes in any one condition will have the potential to impact others.

Like medical and mental health comorbidities, structural inequalities also contribute to COVID-19-HIV syndemics. Food insecurity, for example, can lead to malnutrition, compromise general health status, and impede HIV treatment retention and ART adherence [23, 24]. Likewise, the adverse health effects of food insecurity contribute to risks for severe COVID-19 disease [25]. Housing instability has similar adverse impacts on HIV health outcomes [26], and housing instability can translate to dense congregate living conditions, which can in turn increase COVID-19 exposure risks. For example, in a cohort of marginally housed PLWH in San Francisco, housing instability worsened in early COVID-19 and contributed to increased risks for COVID19-HIV co-infection [27]. Thus, along with mental health and substance use, structural inequalities fall within a syndemics framework and help explain HIV and COVID-19 health disparities.

Previous authors have conceptualized the complex factors influencing the course of HIV infection as interlocking gears, where changes in one cog invariably shift the next $[28,29]$. This same conceptualization can be extended to the whole of HIV syndemics, along with their intersection with COVID-19. Figure 1 illustrates our adaptation of this concept to include the psychosocial sequelae of COVID-19 and their implications for HIV syndemics. In this adaptation, the psychosocial sequelae of COVID-19 such as fear and anxiety of infection, social distancing, and COVID-19 stigma exacerbate mental health conditions such as depression, social isolation, emotional distress, and substance abuse, which in turn contributes to food insecurity, housing instability and poor engagement in healthcare. Furthermore, these synergistic impacts can diminish motivation to engage in COVID-19 mitigation practices, and further suppress immune response, increasing vulnerability to severe COVID-19 [30, 31]. COVID-19 therefore amplifies existing social and health disparities in populations affected by HIV, including those attributed to race, gender, and geographic region [32]. Recognizing that HIV occurs in conjunction with multiple co-occurring epidemics informs clinical and social services as well as creates a framework for research [33]. Our review therefore conceptualizes COVID-19 from the perspective of HIV syndemics by recognizing the synergism of social and behavioral determinants of health that complicate both HIV infection and COVID-19. Our review 
Fig. 1 Conceptualization of COVID-19 and HIV as interlocking conditions in a syndemics framework (adapted from Strathdee et al. (2012) and Pellowski et al., 2013)

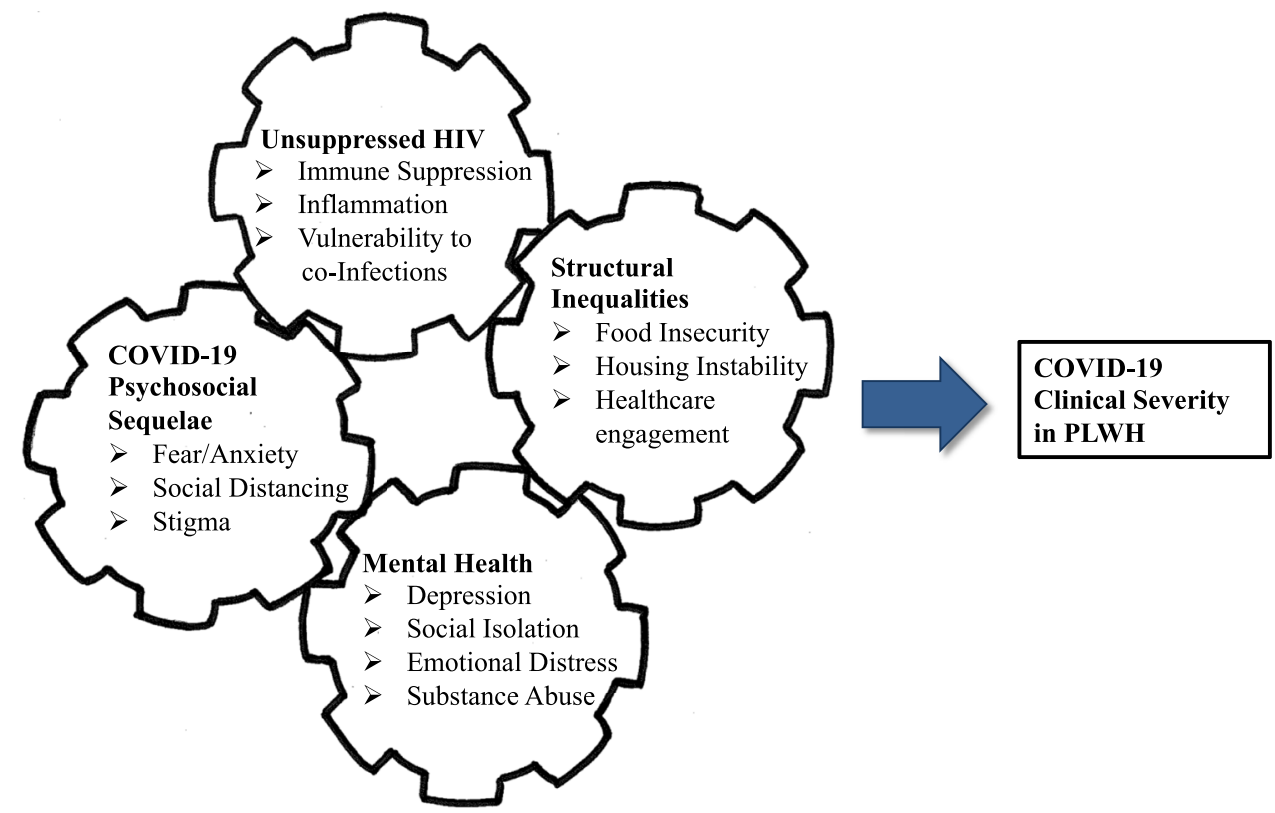

therefore takes syndemics approach to examining the first year of social and behavioral research on the impacts of COVID-19 on PLWH.

\section{Methods}

\section{Search Strategy}

We performed an initial search of PubMed and Google Scholar in March 2021 and repeated the search on May 25, 2021, to assure up-to-date completeness (see Fig. 2). We used a Boolean approach with search terms (hiv) AND (covid-19) AND (depression OR anxiety OR stress OR stigma OR mental health OR alcohol OR drug use OR substance use Or housing OR food insecurity). The first search did not impose time restrictions, and the second search was restricted to papers published between April and May 2021. Following the second search, there were a total of 177 articles identified, and after removing duplicates spanning across search terms, there were 152 articles screened for data-based studies using the titles and abstracts. Furthermore, we conducted a just-in-time manual search of key journals (AIDS Care, AIDS and Behavior, Journal of Acquired Immunodeficiency Syndromes, AIDS Patient Care and STDs, etc.) on November 12, 2021, after the review process and prior to press, identifying an additional 10 studies that are included in the table of study findings. We also removed studies that concerned COVID-19 impacts on HIV but did not include PLWH, such as samples of people at risk for HIV and studies of HIV pre-exposure prophylaxis. A total of 35 studies were included in our review.

\section{Results}

\section{Methodological Considerations}

The studies reviewed from the first year of COVID-19 demonstrated substantial limitations, some of which may have occurred simply because of the obvious time urgency to assess immediate impacts. Thus, studies from the early months of COVID-19 reviewed in this paper cannot tell a complete story of the impacts of COVID-19 on PLWH, as the events of the intersecting pandemics were still evolving. Most of the limitations with these studies are common to cross-sectional research, particularly lacking pre-COVID-19 base rates. Studies reporting high levels of anxiety, depression, social isolation, etc. may not have reflected actual impacts of COVID-19 populations with high base rates. The few studies that reported longitudinal data in this early period suggest that more such studies will become available. Studies that are conducted over time will likely report results from periods included in published cross-sectional studies and will require tracking for redundancy in future reviews. Another limitation in this early literature is the necessity to invent new measures without systematic psychometric development. Again, driven by the immediate urgency of an unfolding pandemic, measures were often developed rapidly and are idiosyncratic to a particular study. Finally, although we reviewed research from the first year of COVID-19, the evolution of the pandemic was not geographically uniform, with research occurring at different stages of local epidemics. Research reported from China, Italy, Spain, the UK, and the USA reflects different stages of COVID-19 in the first year of the pandemic than research from Kenya and 
Fig. 2 Flow of search strategy and resulting papers for this review

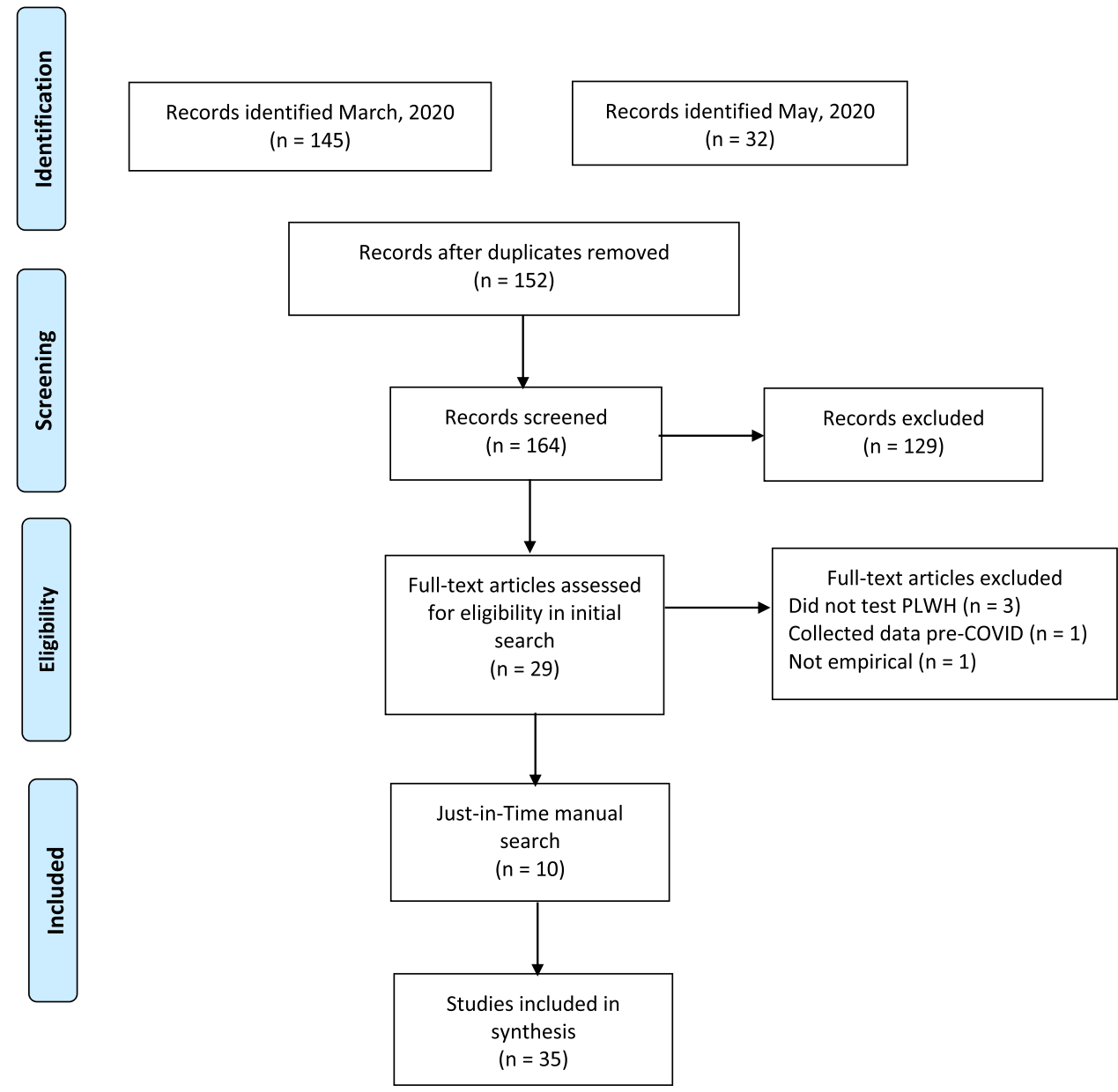

Ukraine. These facets of the literature should be considered as the reviewed research is interpreted.

\section{Mental Health}

Our review of studies concerning the mental health implications of COVID-19 for PLWH identified five major impacts: social isolation, emotional distress, stigma, coping, and substance use (see Table 1).

\section{Social Isolation}

Initial public health responses to COVID-19 emphasized maintaining physical distance to avoid exposure to respiratory droplets and aerosolized virus particles. From a mental health perspective, the common use of the term "social distancing" implied social isolation as an unavoidable consequence of COVID-19 protective behaviors [34]. Cultural differences in living conditions, social relations, and options for interpersonal communication suggest that the social isolating effects of COVID-19 restrictions varied across countries. For example, social relations in Spain emphasize closeness in extended families, frequent gatherings, and community structures for congregating in public spaces, all of which likely helped fuel the devastating early outbreaks of COVID19 in Spain. Ballester-Arnal [35] described COVID-19 as a "socially cruel" disease, with its impacts on social interactions among PLWH compounded by concerns about continuing care and sustaining social support. Similar concerns, as well as evidence for similar COVID-19 impacts among PLWH, were reported in Italy [36]. In Kenya, adolescents and young adults living with HIV indicated that the greatest impacts of COVID-19 were those that restricted social interactions, including $25 \%$ of young people stating that closed churches and $92 \%$ of young people stating that closed schools were the greatest adverse impacts of COVID-19 they experienced [37]. However, the adverse social impacts of COVID-19 restrictions were not universal. In Australia, for example, $43 \%$ of PLWH reported that COVID-19 negatively impacted social relationships, while $13 \%$ reported that COVID-19 had a positive impact on their relationships [38].

Cultural variations notwithstanding, PLWH may have been particularly vulnerable to the adverse effects of social isolation given the limited social support they often experience due to HIV stigma and intersecting sources of rejection (e.g., racism, homophobia, sexism). For example, one study 


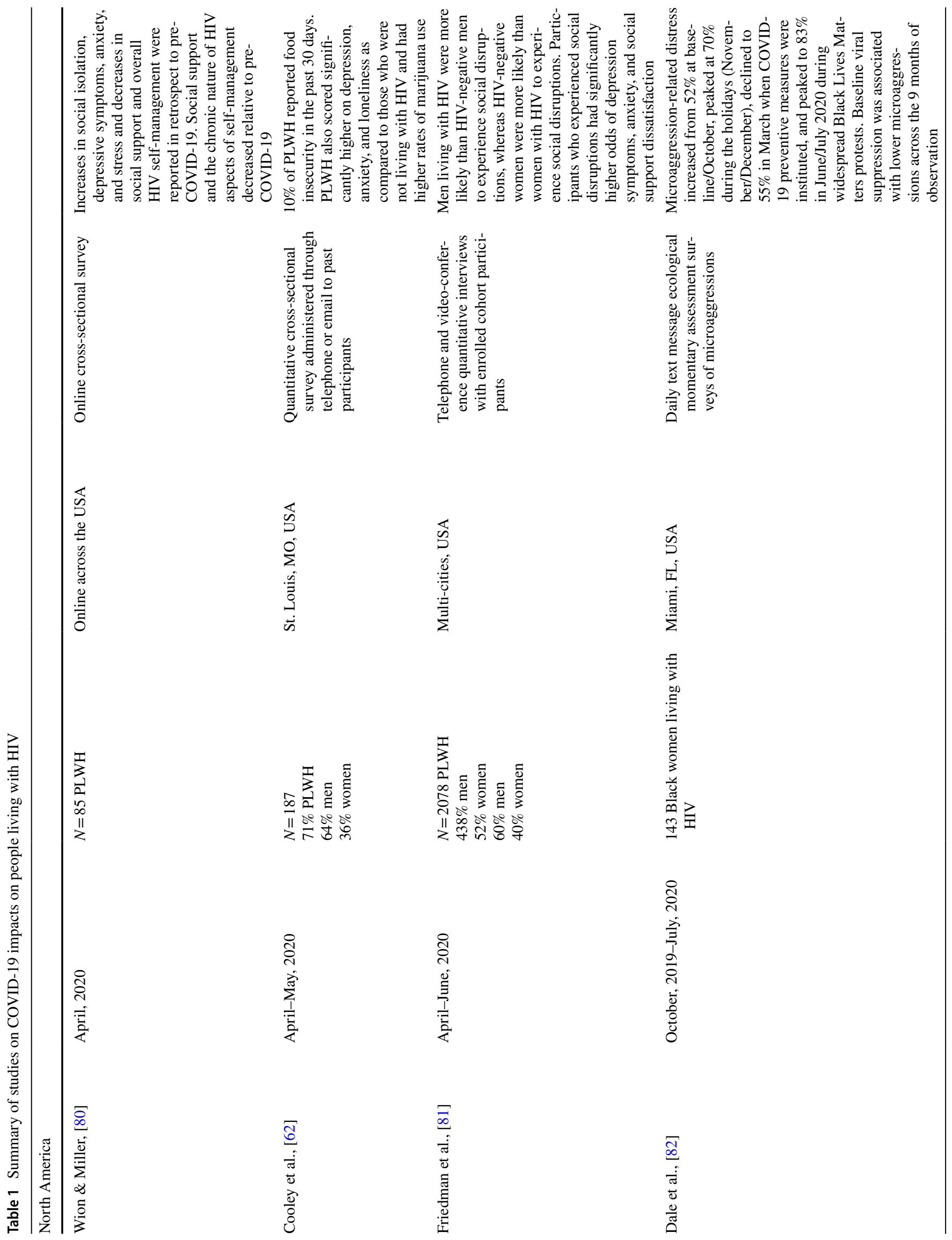



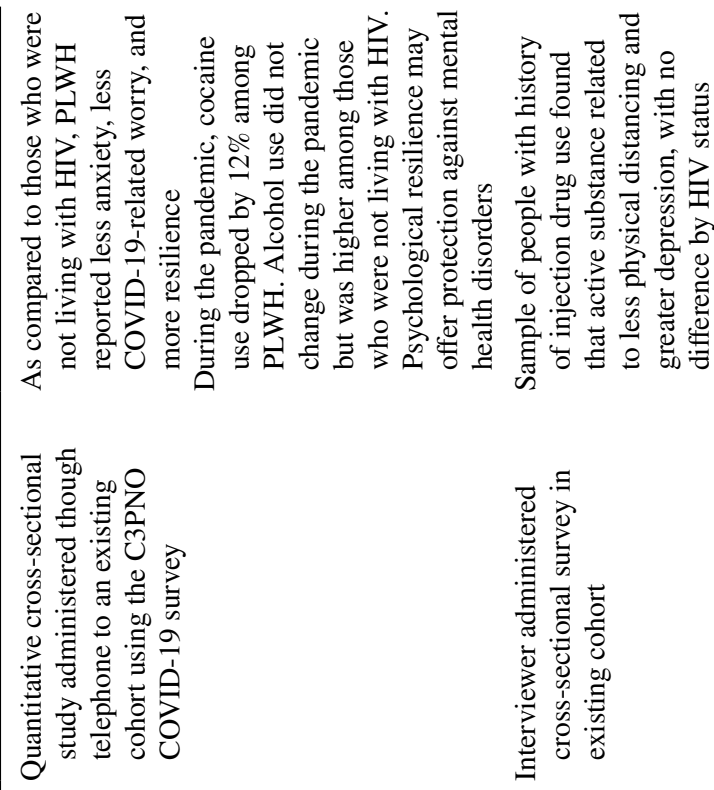

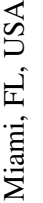

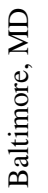

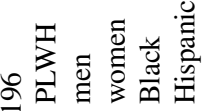

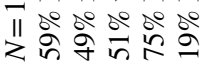

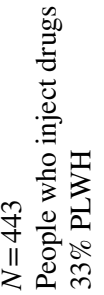

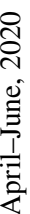

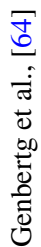




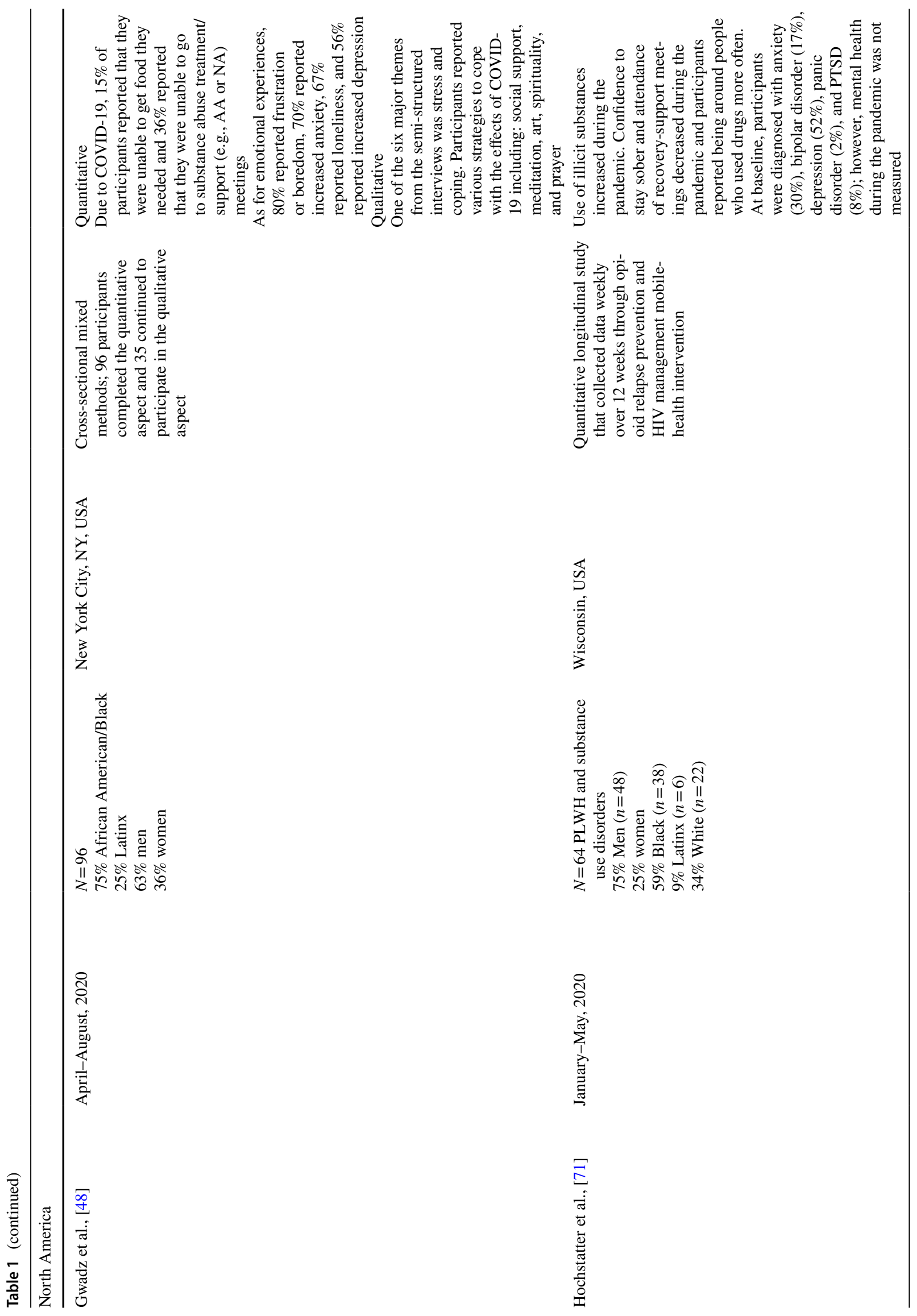




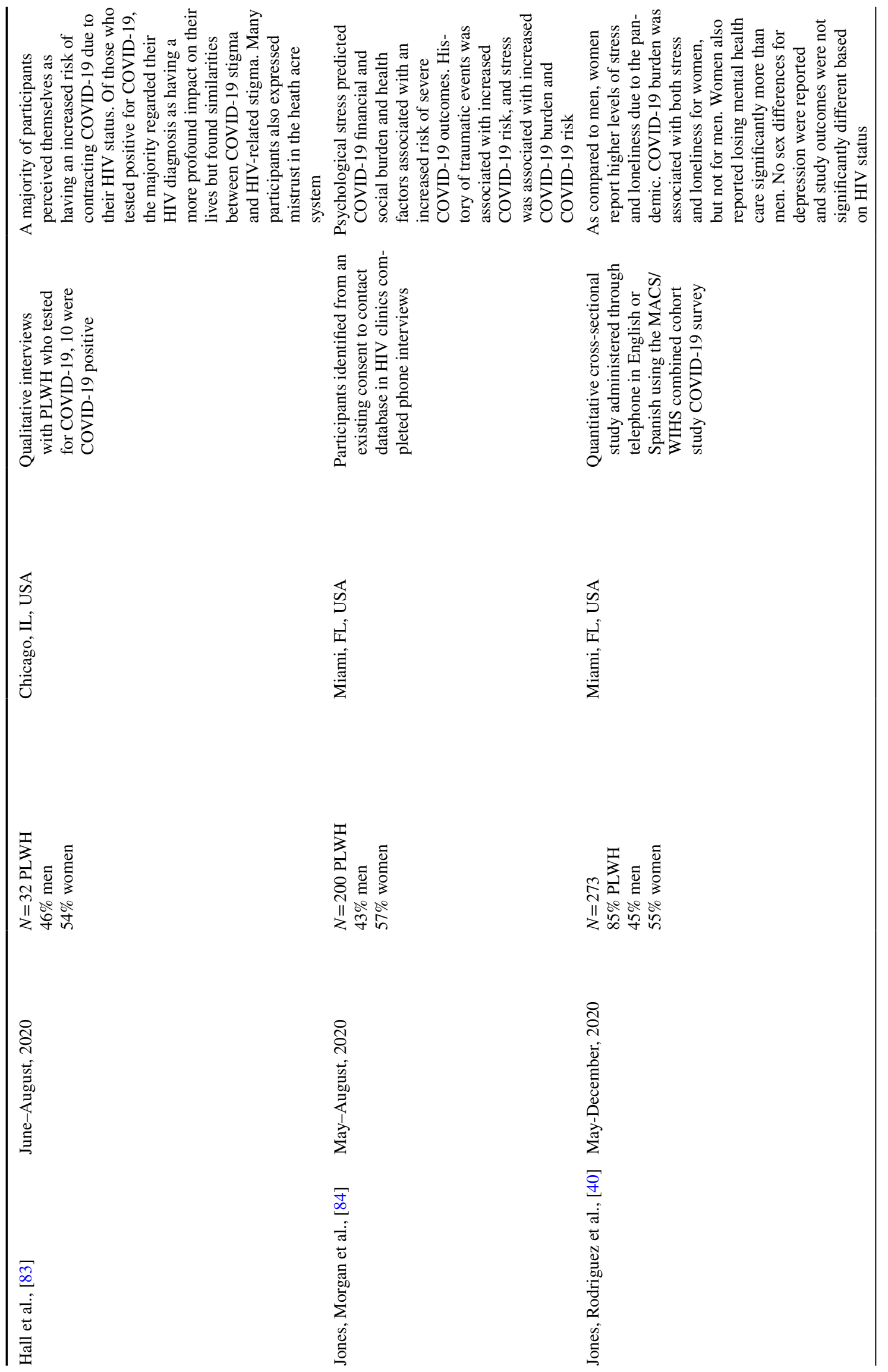




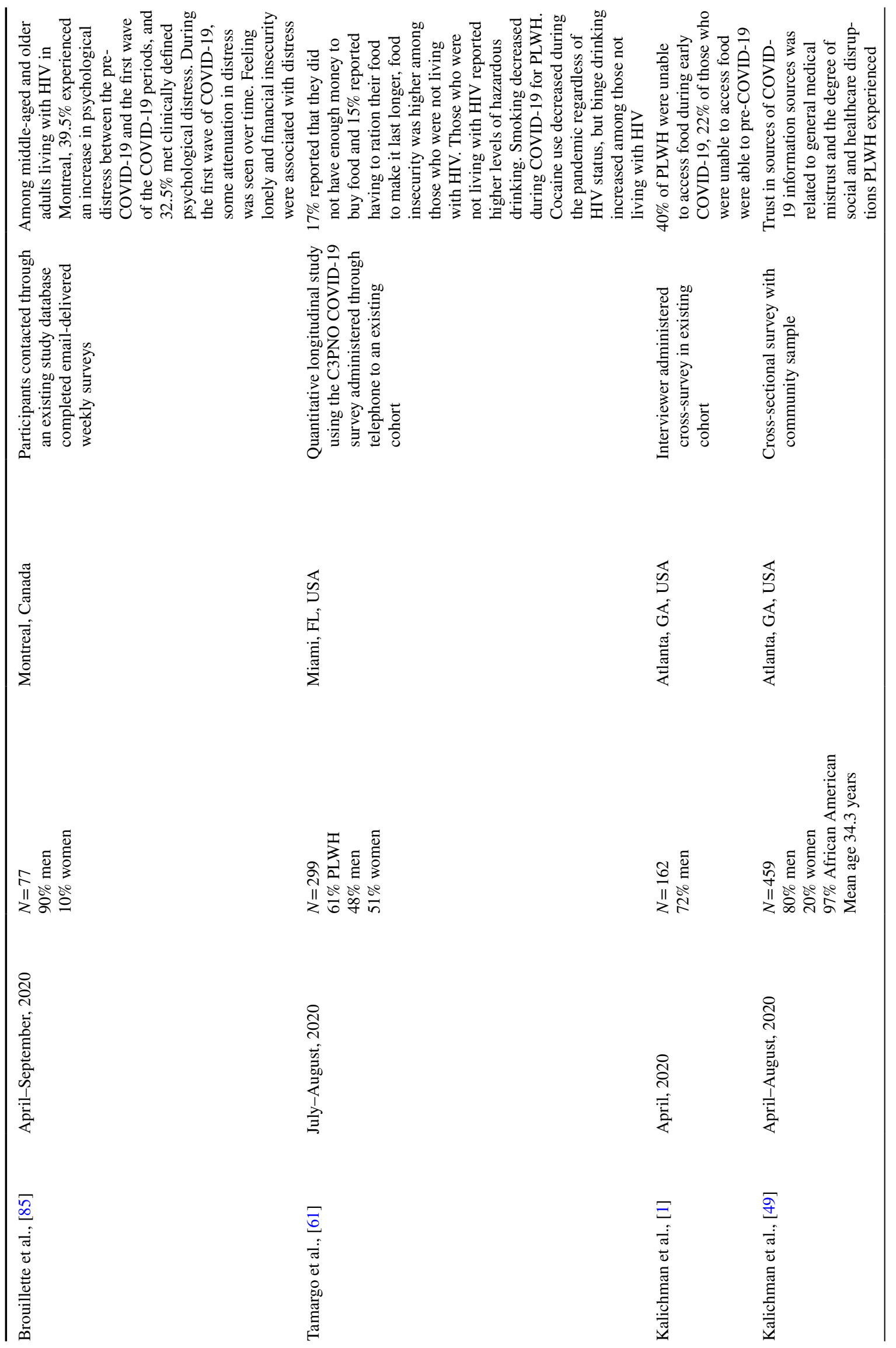




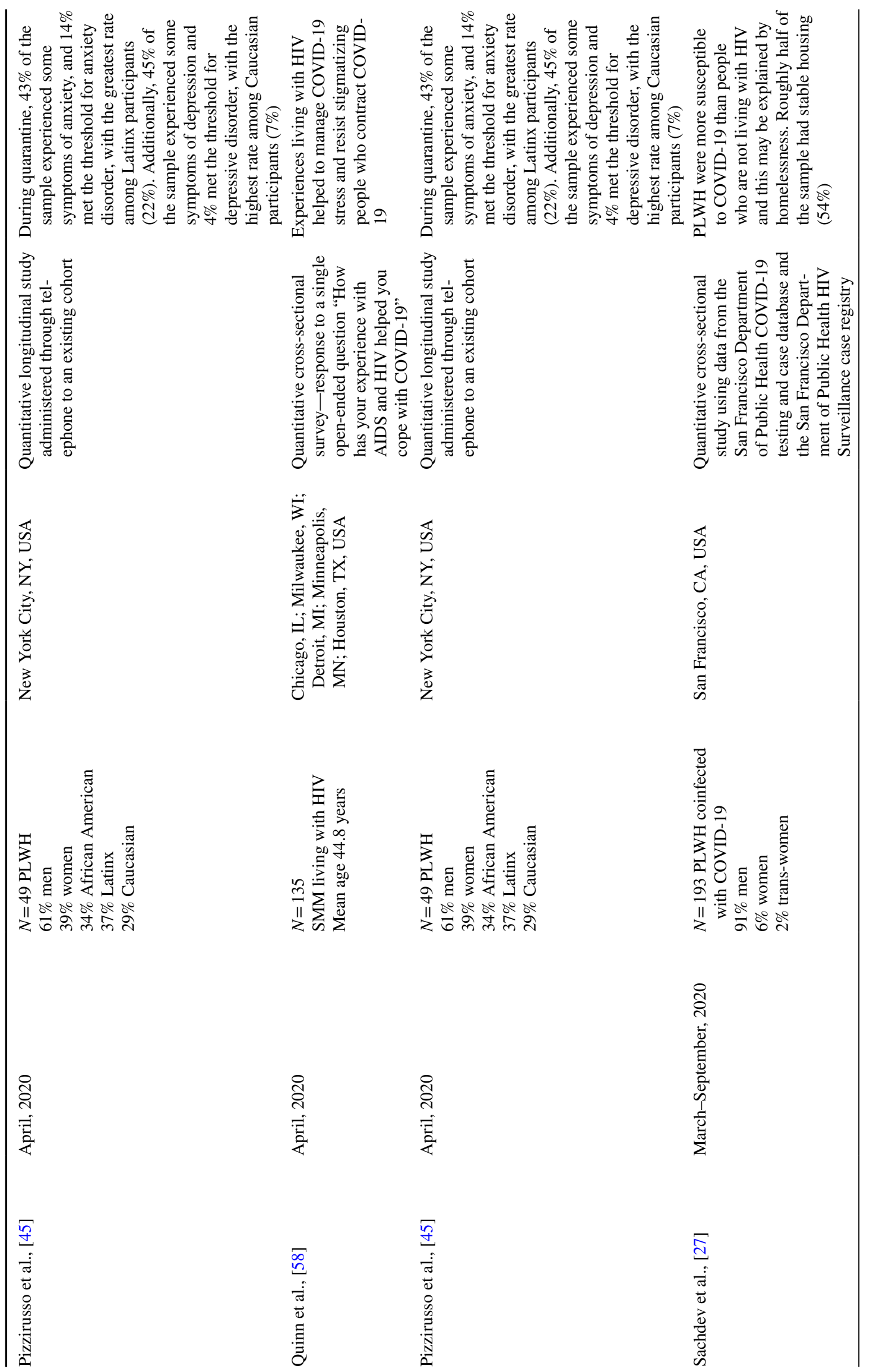




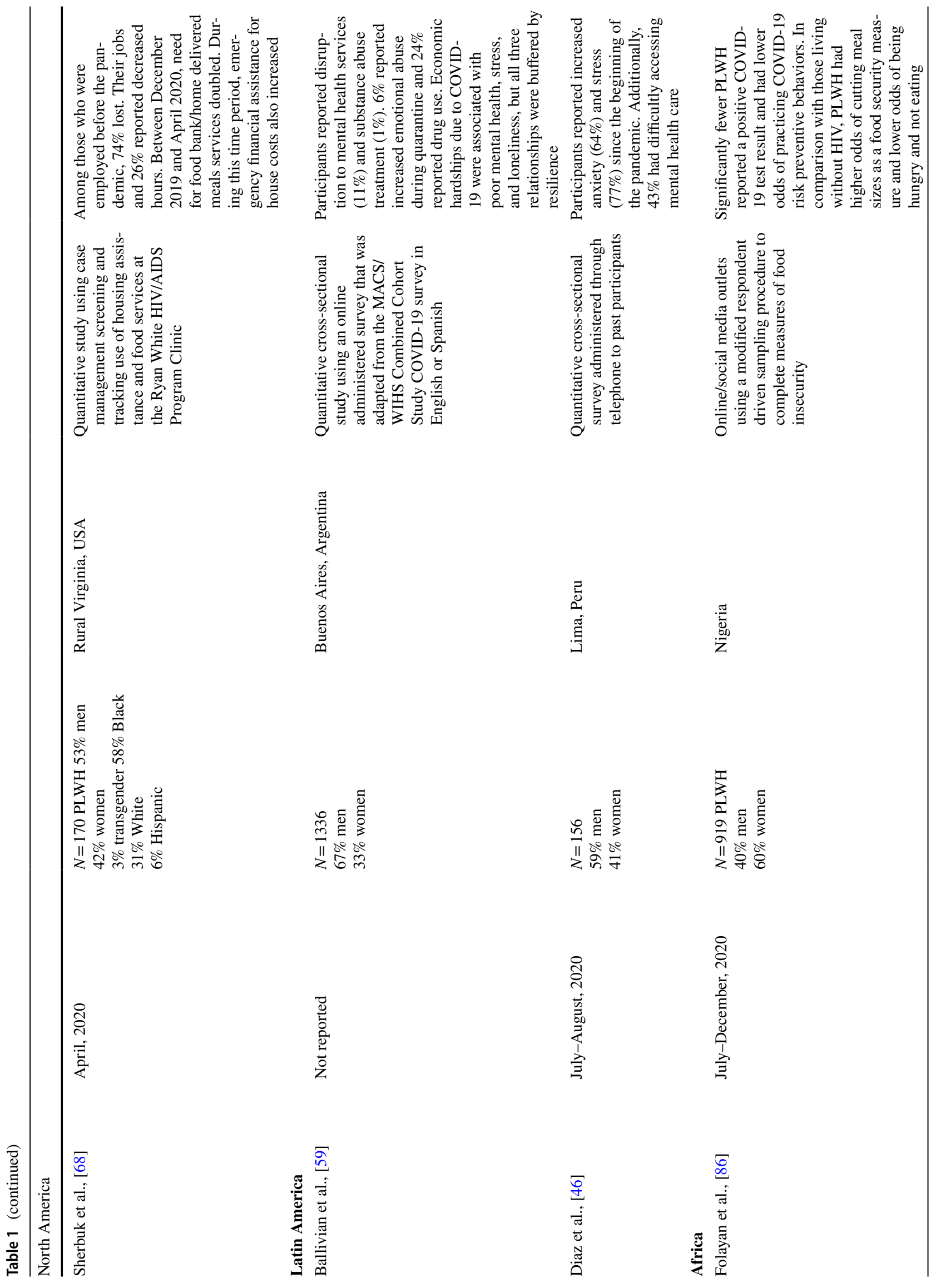




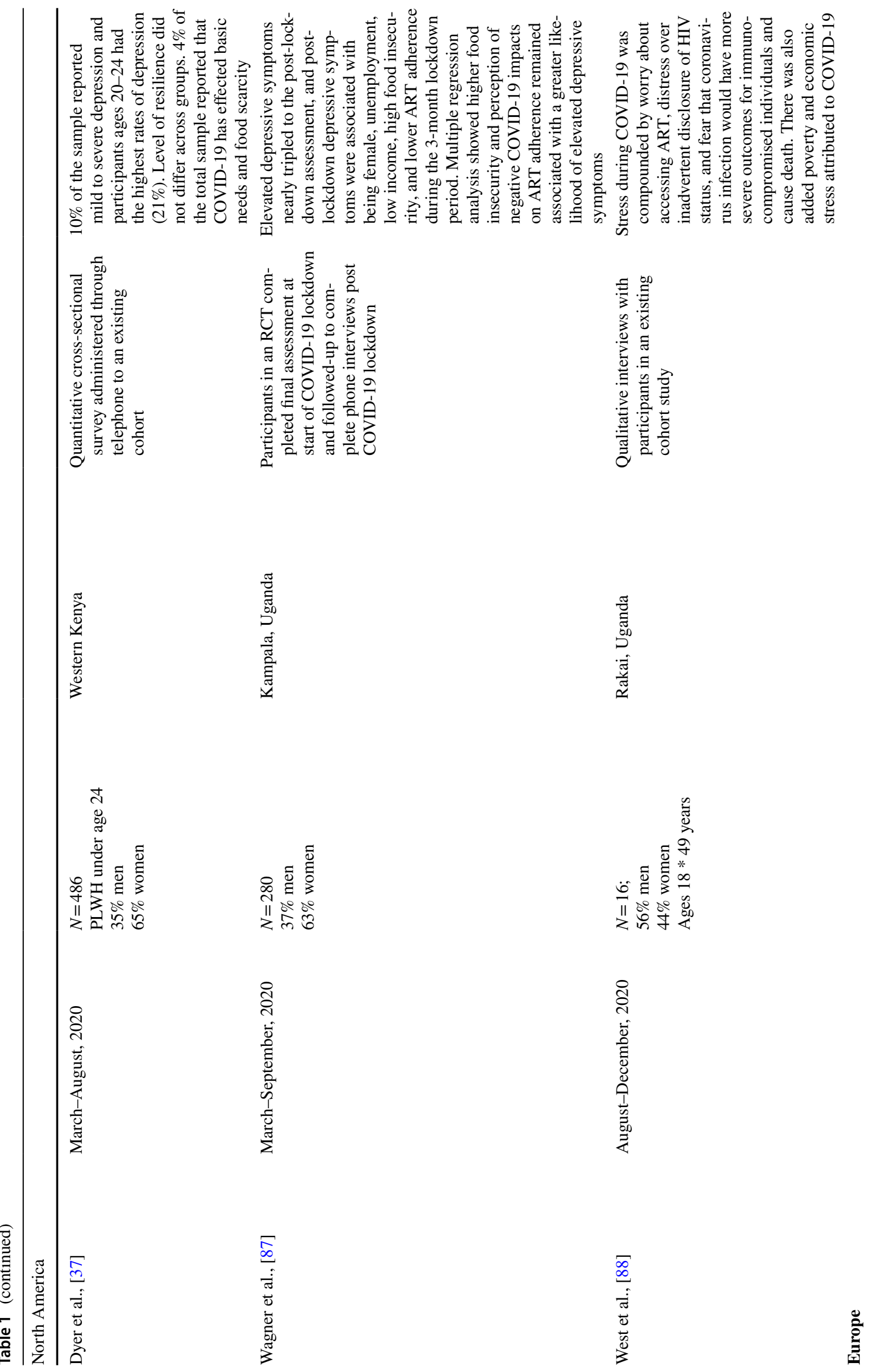




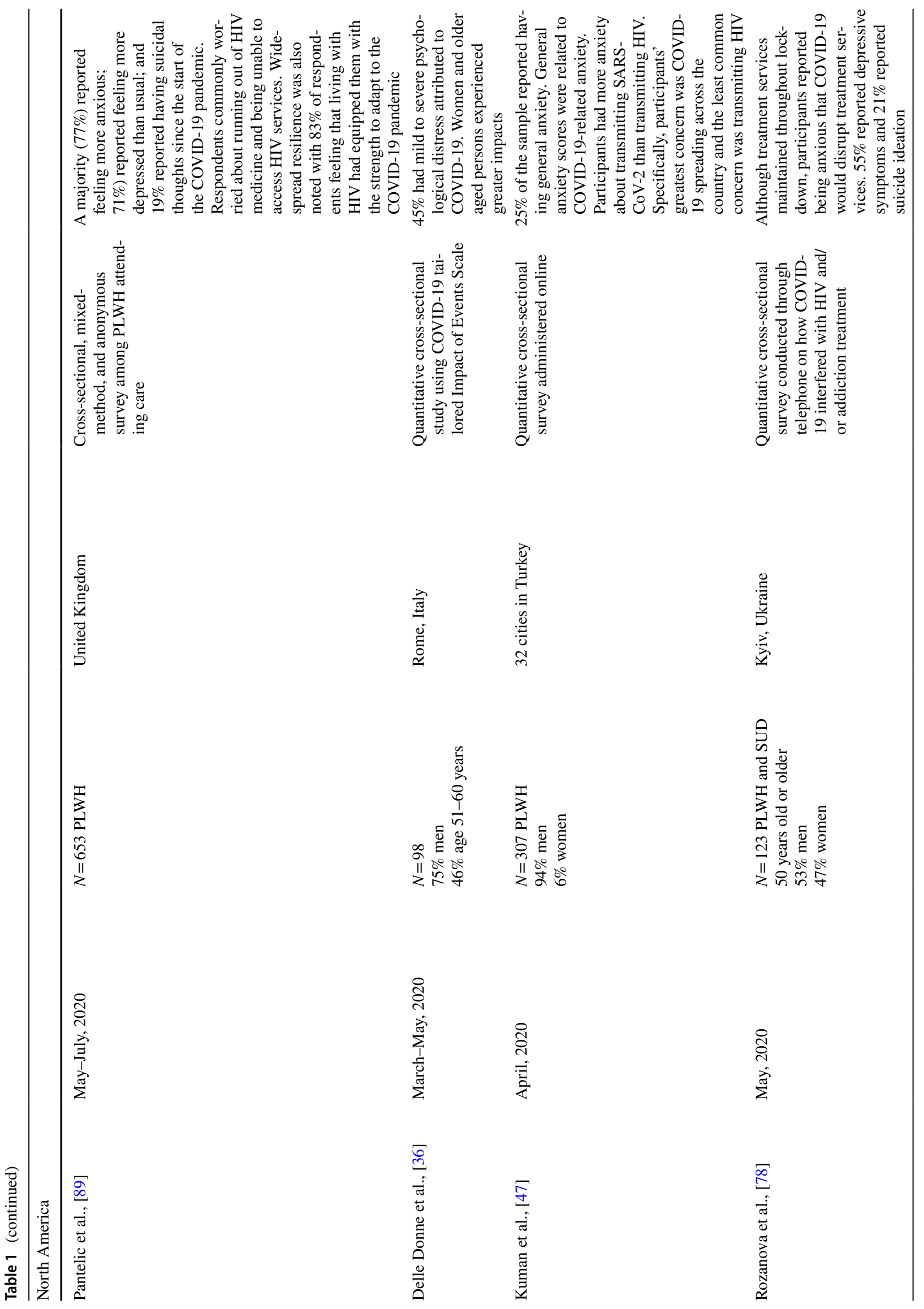




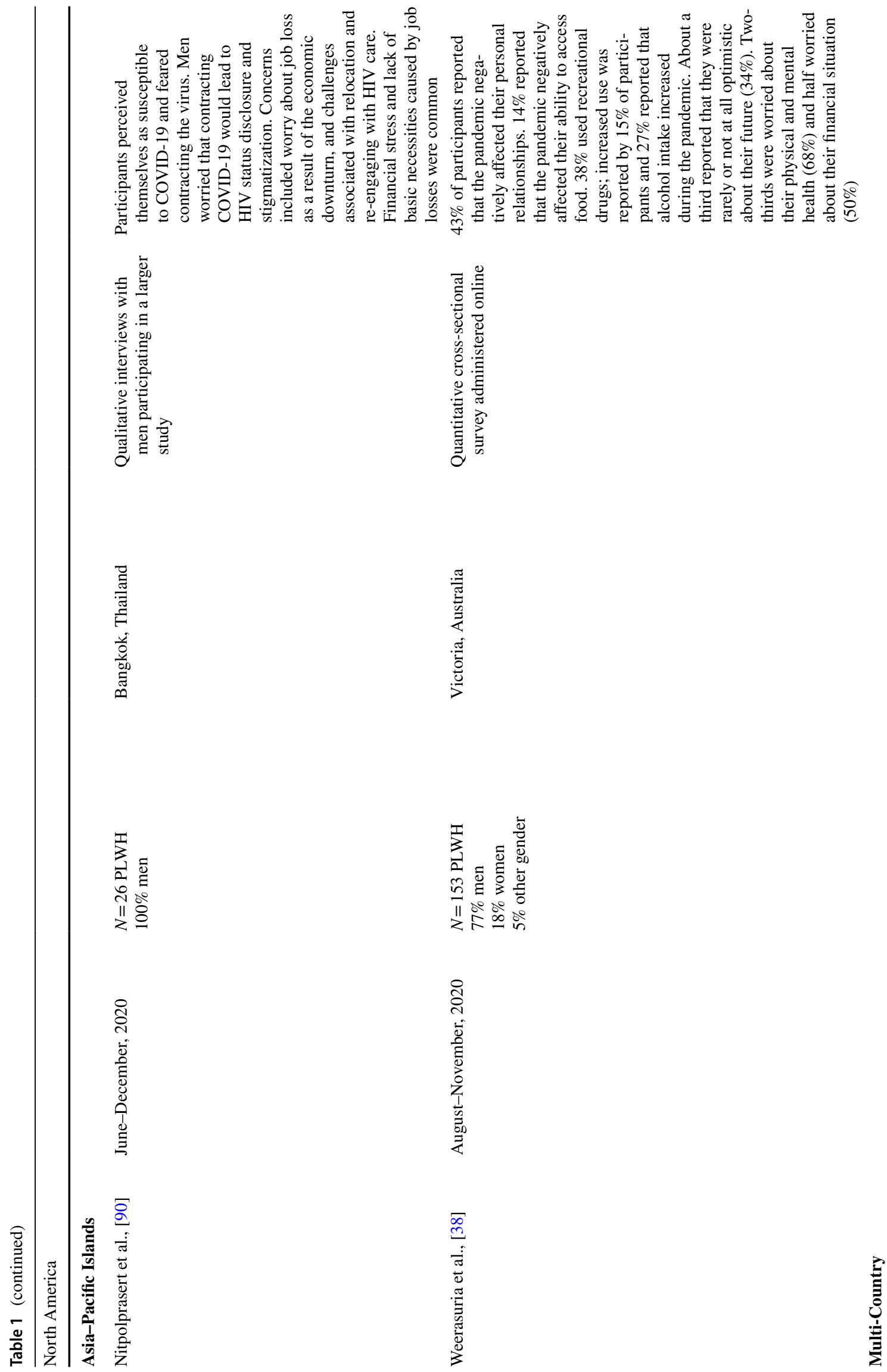




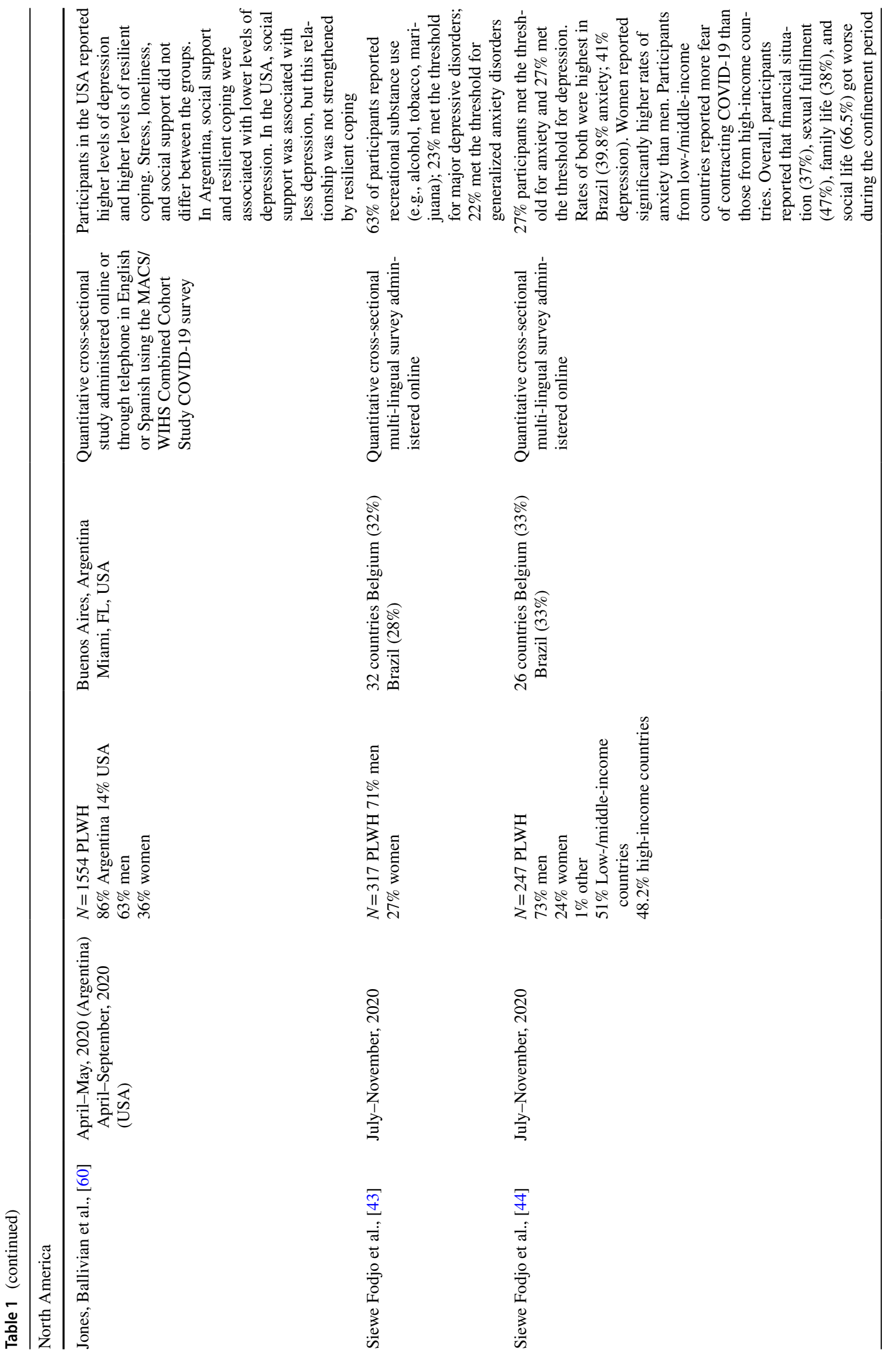


reported that $72 \%$ of PLWH participating in a longitudinal cohort were already socially isolated, defined as living alone, not engaged in a relationship, lacking reliable sources of social support, and not being socially satisfied [18]. Subsequent data collection during early COVID-19 found that having recently experienced violence and having a mental illness were correlates of increased social isolation [39]. Other research conducted early in the COVID-19 pandemic reported increased loneliness among PLWH and suggested greater loneliness and stress among women than men [40]. However, there were PLWH who received increases in social support during COVID-19 lockdowns as service providers ramped up outreach efforts and PLWH and HIV care providers became technologically connected [41]. The duration of social isolation and loneliness experienced by PLWH during early COVID-19 may have been relieved as services, communities, and individuals adapted to socially distant communication [42].

\section{Emotional Distress}

People living with HIV are typically attuned to the fact that they can be more vulnerable to an array of infectious diseases. Increased vulnerability to co-infections, as well as non-infectious comorbidities, in the daily lives of PLWH provides a basis for the increased stress that was attributable to COVID-19 for many PLWH. Some studies in early COVID-19 reported high rates of depression and anxiety among PLWH [43, 44], although it is not possible to know if these rates in-and-of themselves represent a change from pre-COVID19 levels of distress. However, in Australia, twothirds of PLWH reported worrying about their health and mental health specifically due to COVID-19 [38]. Other studies that were also able to account for pre-COVID-19 mental health examined changes over time and offer clearer answers. For example, a study of PLWH in New York City found $69 \%$ of PLWH experienced symptoms of emotional distress with $4 \%$ meeting the threshold for major depression and $14 \%$ meeting the criteria for general anxiety disorder during periods of quarantine and lockdown, and emotional distress were partly attributable to prior diagnoses of anxiety and depression [45]. In Peru, PLWH reported experiencing increases in anxiety and stress that they retrospectively attributed to changes in their lives resulting from early COVID-19 [46]. Similarly, one in four PLWH in Turkey reported general anxiety during early COVID-19. In this study, non-specific general anxiety was related to anxiety specifically attributed to COVID-19, and increased anxiety seemed to result from concerns about the transmissibility of COVID-19 [47]. During Italy's early and severe COVID-19 outbreak, anxiety and stress were greatest among PLWH with additional underlying comorbidities [36]. 
Two studies concerning the emotional distress of COVID19-HIV are particularly noteworthy for their methodological approaches. The first study built on assessments that were being conducted weekly before COVID-19 and continued during the outbreak. In this study, older adults living with HIV expressed concerns about potential exposures to COVID-19 and these concerns were the leading source of stress during the early weeks of COVID-19 [41]. In the second study, researchers used an adaptation of the Impact of Events Scale that specified COVID-19 as the impactful event. In this study, Delle Donne et al. [36] found that $45 \%$ of participants reported mild to severe symptoms of distress, most commonly depression and anxiety attributable to COVID-19, with greater emotional distress reported by women than men.

Studies also investigated factors that may have contributed to increased COVID-19 distress. For example, because of heightened concerns for contracting COVID-19 among PLWH, conflicting public health messaging and misinformation may have fueled COVID-19 stress [48]. One barrier to COVID-19 information messaging was a lack of trust in public health information sources, such as the CDC and health departments. Using the same measures, two independent studies showed that PLWH in New York City [48] and Atlanta, GA [49], demonstrated low levels of trust in COVID-19 information from all public health institutions, with greater trust in local and state health departments than trust in the CDC and other federal agencies. It is important to note that like social isolation, not all studies provide evidence for adverse effects of COVID-19 on emotional distress among PLWH. Specifically, in Miami, FL PLWH demonstrated less anxiety and COVID-19-related worries than a comparison group of people not living with HIV, and the difference was associated with resilience that served to buffer anxiety [50].

\section{Stigma}

Fueled by fear, stigma is an expected consequence of infectious disease outbreaks and serves as another source of COVID-19 stress for PLWH [51]. Past experience with emergent infectious diseases, including H1N1 influenza [52] and SARS [53], provided the groundwork for what to expect with regard to COVID-19 stigma. Characterizing a new infectious disease as originating from outsiders facilitates a process of "othering," which reinforces the social construction of illness as a foreign invasion with ensuing xenophobia [34]. Because HIV itself is a highly stigmatized condition, stigmas attached to COVID-19 may be particularly stressful for PLWH. Among PLWH, endorsing prejudicial and discriminating attitudes toward COVID-19 is associated with greater concern over contracting COVID-19 and a greater likelihood of implementing social distancing to prevent contracting COVID-19 [54, 55].

Along with HIV stigma, intersecting sources of social inequality have contributed to and have compounded the stress of COVID-19 for PLWH. In qualitative interviews, Gwadz et al. [48] found that experiences of racism and structural inequality often framed PLWH's experiences with COVID-19. Participants in this study saw a direct link between their experiences living with HIV and COVID-19 health disparities. Just as would be true for people not living with HIV, fear of COVID-19 exposure may have also been greater among PLWH in cities and densely populated areas where social distancing is more difficult [48]. Interruptions to health services and medications as well as anticipated and actual loss of income attributed to COVID-19 also contributed to stress experienced by PLWH. A study of sexual minority men from 103 counties found that $46 \%$ of men living with HIV anticipated loss of income due to COVID19 compared to $38 \%$ of men who were not living with HIV, which was a significant difference [56]. And while anxiety and depression did not differ between the two HIV status groups, anticipated loss of income was associated with overall anxiety and depression.

\section{Adaptive Coping}

Although the risk for severe COVID-19 is greater for people with HIV, prior experiences living with HIV may serve as a source of resilience for some PLWH. For example, contrary to expectations that PLWH would be adversely affected by COVID-19 stigma [57], Quinn et al. [58] found that men living with HIV believed that having lived through the HIV pandemic helped them manage the stress brought about by COVID-19, including resisting stigmatizing people who contract COVID-19 and facilitating a sense of responsibility for preventing the spread of COVID-19. In Argentina, resilience (defined as responding adaptively to adversity), buffered the association between economic hardship incurred during COVID-19 and perceived COVID-19 stress and loneliness [59]. Resilience has therefore emerged as a key characteristic of adaptive coping with COVID-19, including limiting the adverse effects that COVID-19 has on the mental health and well-being of PLWH [50,60]. Like other aspects of COVID-19 impacts, there are cultural differences in the influence that resilience has on coping with COVID19 in PLWH, with resilient coping reducing depression in PLWH in Argentina, but not in the USA [60]. While there were no studies concerning aspects of adaptive coping other than resilience, studies did consider substance use as a maladaptive coping strategy. 


\section{Substance Use}

The emotional distress of COVID-19 has the potential to prompt increased substance use and relapse to use among individuals in recovery. Increased substance use carries several detrimental implications for the health of PLWH. Studies that examined substance use among PLWH during early COVID-19 reported variable results with no consistent pattern. Some studies reported increases in alcohol consumption [38, 61] and other drug use [44], although it is unclear if these increases differed from those of people not living with HIV. Counter to expectations, some studies reported reductions in drug use among PLWH, including tobacco consumption $[50,61]$. There is also mixed evidence for increased adverse consequences from COVID-19 that are expected with increased substance use. Using a 30-day retrospective assessment strategy during early COVID-19, PLWH reported greater marijuana use compared to their HIV-negative counterparts, including a greater increases in use since a previous pre-COVID-19 assessment, and greater use was associated with depression symptoms [62]. In contrast, a study of PLWH in the state of Wisconsin found that while alcohol and marijuana use did not increase during early COVID-019, use of other drugs nearly doubled from $10 \%$ reporting use to $18 \%$ [63]. Among people who inject drugs, active substance use was associated with less physical distancing to prevent COVID-19 and greater depression, with no differences between participants living with HIV and those not living with HIV [64].

\section{Structural Inequalities}

Three major COVID-19 impacts on structural inequalities were assessed in the early COVID-19 studies: food insecurity, housing instability, and accessing health services.

\section{Food Insecurity and Housing Instability}

Food insecurity increased in the general US population during early COVID-19, specifically between March and June 2020 by as much as 10\% [21]. Decades of research has reported that PLWH have high rates of both food insecurity and housing instability [23, 65, 66], making PLWH a particularly vulnerable population for COVID-19 disruptions in food access and housing security. The impacts of COVID-19 on food security and housing stability were therefore expected to be greater than in other populations, with the greatest disruptions occurring for the least resourced [67]. People living with HIV themselves anticipated greater loss of financial support due to COVID-19 than did people not living with HIV, and the anticipated financial losses were expected to increase depression and anxiety. However, despite no differences between PLWH and their HIV-negative counterparts in terms of job loss or salary reductions during COVID-19, PLWH reported greater increases in financial stress and food insecurity [62]. One study in New York City found that $14 \%$ of PLWH were unable to obtain food they needed during the early months of COVID-19 [48]. In St. Louis, Missouri, during the early months of COVID-19, PLWH experienced greater food insecurity including not having enough food they needed and experiencing hunger, than their HIV-negative counterparts [62]. In another major US city, Atlanta, GA, $40 \%$ of PLWH reported not being able to access food during the early weeks of COVID-19, with one in five food-insecure participants becoming food insecure during early COVID-19 [1]. For patients receiving Ryan White Care services in a rural area of the Southern United States, $69 \%$ of patients who had been employed prior to COVID-19 reported adverse impacts on their employment, including $74 \%$ of those patients losing their jobs. In addition, Ryan White services for food support increased $66 \%$ and emergency housing services increased 69\% in April 2020 [68].

Similar vulnerabilities to structural inequalities exacerbated by COVID-19 were observed across continents. Among young PLWH in Kenya, 25\% reported that the early COVID-19 impacted their employment and income [37]. Similarly, 25\% of PLWH in Australia reported negative effects of COVID-19 on their incomes [38]. In addition, $13 \%$ of PLWH in Australia indicated that they experienced reductions in access and affordability of food during periods of COVID-19 restrictions [38]. In Argentina, the rate of PLWH experiencing financial hardship during COVID-19 was $41 \%$ [59].

\section{Access to Health Services}

Among the most consistent research findings for PLWH during early COVID-19 were concerns that lockdowns would reduce access to HIV care services. Disruptions to clinical and social services were reported during the earliest days of local responses to COVID-19 [42, 69, 70]. Even when services themselves were available, PLWH expressed concern about losing access and lacked confidence that they could attend upcoming appointments because of COVID19-related restrictions [71]. Clinic and pharmacy closures had an obvious short-term effect on all patients, including those living with HIV. One factor contributing to healthcare interruptions was trust in public health guidelines. In a study 459 people living with HIV in Atlanta, expressing greater trust in the CDC for COVID-19 information was related to experiencing fewer disruptions to healthcare, suggesting that PLWH were positively impacted by trusting credible COVID-19 information [49].

The impacts of early COVID-19 disruptions on ART adherence also varied across studies. It was widely expected 
that COVID-19 would interrupt access to ART with adverse effects on adherence, particularly given ubiquitous disruptions to accessing care, pharmacies, and the impacts on factors known to influence adherence, such as stress and substance use [72]. Globally, an estimated one in five PLWH were unable to access their HIV care provider, and close to half of PLWH were unable to access ART refills remotely, with the least access occurring in Belarus, Brazil, Kazakhstan, Mexico, and Russia [73]. During the early weeks of COVID-19, Hochstatter et al. [71] reported that $12 \%$ of participants missed taking their ART as compared to 5\% during pre-pandemic assessments. Similarly, in Argentina $8 \%$ of PLWH were unable to take their ART during early COVID-19 [40].

However, adverse impacts of COVID-19 on ART adherence are not universal. In Australia, 99\% of PLWH were able to access their ART without interruption [43]. Some studies reported increased ART adherence during early COVID19. In Atlanta, Kalichman et al. [1] found that adherence increased in a sample of young PLWH from 53\% of ART taken pre-COVID-19 to $78 \%$ taken in the first months of COVID-19. In New York City, Gwadz et al. [48] also reported some PLWH improving adherence in early COVID19, with shelter-in-place orders, increased daily routines, and health consciousness forming a basis for improved adherence.

There is little evidence that substance use treatment and harm reduction services were disrupted in the early months of COVID-19 [74-76], while HIV testing may have increased in these settings [77]. Finally, in a study of older adults receiving ART, $42 \%$ of participants with substance use disorders, individuals reported being able to sustain ART adherence and substance use treatment during periods of early COVID-19 lockdowns, despite feedings of anxiety and social isolation [78].

\section{Conclusions}

The COVID-19 pandemic impacts the mental health and structural inequalities of PLWH, and these impacts can be conceptualized within the context of HIV syndemics. However, the degree to which COVID-19's impacts on PLWH varied from individuals not living with HIV is unclear. Greater risks for severe COVID-19 among PLWH, especially persons who are not HIV suppressed and/or have HIV comorbidities, suggest that the impacts would be greater for PLWH. However, studies that included both PLWH and people not living with HIV found few consistent differences in COVID-19 impacts. One reliable exception was the greater impact of COVID-19 on the persistent healthcare of PLWH. Greater disruption to services would be expected for PLWH given that they are managing a chronic illness that relies on regular contact with health services. The adverse effects of healthcare disruptions along with risk for severe COVID19 were among the greatest concerns expressed by PLWH. Because COVID-19 is still evolving, with different countries at varying stages in their epidemiology and vaccination rates, understanding the long-term impacts of COVID-19 will require additional research and future reviews. While studies conducted in the first year of the COVID-19 outbreak did not demonstrate clear patterns of impact on mental health and substance use, and some impacts expected by commentators were not fully realized, such as increases in depression, stigma [2], and interpersonal violence [59, 79], future research on the co-occurring COVID-19 and HIV pandemics may tell a different story.

Funding National Institute of Mental Health Grant R01-MH121129 and R01-DA043068.

\section{Declarations}

Conflict of Interest The authors declare no competing interests.

\section{References}

1. Kalichman SC, Eaton LA, Berman M, Kalichman MO, Katner $\mathrm{H}$, Sam SS, et al. Intersecting pandemics: impact of SARSCoV-2 (COVID-19) protective behaviors on people living with HIV, Atlanta, Georgia. J Acquir Immune Defic Syndr. 2020;85(1):66-72.

2. Eaton LA, Kalichman SC. Social and behavioral health responses to COVID-19: lessons learned from four decades of an HIV pandemic. J Behav Med. 2020;43(3):341-5.

3. Bhaskaran K, Rentsch CT, MacKenna B, Schultze A, Mehrkar A, Bates CJ, et al. HIV infection and COVID-19 death: a population-based cohort analysis of UK primary care data and linked national death registrations within the OpenSAFELY platform. Lancet HIV. 2021;8(1):e24-32.

4. Ssentongo P, Heilbrunn ES, Ssentongo AE, Advani S, Chinchilli VM, Nunez JJ, et al. Epidemiology and outcomes of COVID-19 in HIV-infected individuals: a systematic review and meta-analysis. Sci Rep. 2021;11(1):6283.

5. Boffito M, Waters L. More evidence for worse COVID-19 outcomes in people with HIV. Lancet HIV. 2021;8(11):e661-2.

6. Yang X, Sun J, Patel RC, Zhang J, Guo S, Zheng Q, et al. Associations between HIV infection and clinical spectrum of COVID-19: a population level analysis based on US National COVID Cohort Collaborative (N3C) data. Lancet HIV. 2021;8(11):e690-700.

7. Eisinger RW, Lerner AM, Fauci AS. HIV/AIDS in the Era of COVID-19: A Juxtaposition of Two Pandemics. J Infect Dis. 2021;224(9):1455-61.

8. Laurence J. Why aren't people living with HIV at higher risk for developing severe coronavirus disease 2019 (COVID-19)? AIDS Patient Care STDS. 2020;34(6):247-8.

9. Ambrosioni J, Blanco JL, Reyes-Uruena JM, Davies MA, Sued O, Marcos MA, et al. Overview of SARS-CoV-2 infection in adults living with HIV. Lancet HIV. 2021;8(5):e294-305. 
10. Del Amo J, Polo R, Moreno S, Diaz A, Martinez E, Arribas $\mathrm{JR}$, et al. Incidence and severity of COVID-19 in HIV-positive persons receiving antiretroviral therapy. Ann Intern Med. 2021;174(4):581-2.

11. Winwood JJ, Fitzgerald L, Gardiner B, Hannan K, Howard C, Mutch A. Exploring the social impacts of the COVID-19 pandemic on people living with HIV (PLHIV): a scoping review. AIDS Behav. 2021;25(12):4125-40.

12. Moradi-Marjaneh R, Asgharzadeh F, Khordad E, Marjaneh MM. Diabetes and COVID-19; a review of possible mechanisms. Curr Pharm Des. 2021;27(21):2522-7.

13. Corona G, Pizzocaro A, Vena W, Rastrelli G, Semeraro F, Isidori AM, et al. Diabetes is most important cause for mortality in COVID-19 hospitalized patients: Systematic review and metaanalysis. Rev Endocr Metab Disord. 2021;22(2):275-96.

14. Tartof SY, Qian L, Hong V, Wei R, Nadjafi RF, Fischer H, et al. Obesity and mortality among patients diagnosed with COVID19: results from an integrated health care organization. Ann Intern Med. 2020;173(10):773-81.

15. Mirzaei H, McFarland W, Karamouzian M, Sharifi H. COVID19 among people living with HIV: a systematic review. AIDS Behav. 2021;25(1):85-92.

16. Willig AL, Overton ET. Metabolic complications and glucose metabolism in HIV infection: a review of the evidence. Curr HIV/AIDS Rep. 2016;13(5):289-96.

17. Friedman MR, Sang JM, Bukowski LA, Matthews DD, Eaton LA, Raymond HF, et al. HIV care continuum disparities among Black bisexual men and the mediating effect of psychosocial comorbidities. J Acquir Immune Defic Syndr. 2018;77(5):451-8.

18. Marziali ME, Card KG, McLinden T, Wang L, Trigg J, Hogg RS. Physical distancing in COVID-19 may exacerbate experiences of social isolation among people living with HIV. AIDS Behav. 2020;24(8):2250-2.

19. Shiau S, Krause KD, Valera P, Swaminathan S, Halkitis PN. The burden of COVID-19 in people living with HIV: a syndemic perspective. AIDS Behav. 2020;24(8):2244-9.

20. Singer M, Clair S. Syndemics and public health: reconceptualizing disease in bio-social context. Med Anthropol Q. 2003;17(4):423-41.

21. Nagata JM, Ganson KT, Whittle HJ, Chu J, Harris OO, Tsai AC, et al. Food insufficiency and mental health in the U.S. during the COVID-19 pandemic. Am J Prev Med. 2021;60(4):453-61.

22. Bonn M, Palayew A, Bartlett S, Brothers TD, Touesnard N, Tyndall $\mathrm{M}$. Addressing the syndemic of HIV, hepatitis $\mathrm{C}$, overdose, and COVID-19 among people who use drugs: the potential roles for decriminalization and safe supply. J Stud Alcohol Drugs. 2020;81(5):556-60.

23. Weiser SD, Frongillo EA, Ragland K, Hogg RS, Riley ED, Bangsberg DR. Food insecurity is associated with incomplete HIV RNA suppression among homeless and marginally housed HIV-infected individuals in San Francisco. J Gen Intern Med. 2009;24(1):14-20.

24. Weiser SD, Fernandes KA, Brandson EK, Lima VD, Anema A, Bangsberg DR, et al. The association between food insecurity and mortality among HIV-infected individuals on HAART. J Acquir Immune Defic Syndr. 2009;24(8):2244-9.

25. Perez-Escamilla R, Cunningham K, Moran VH. COVID-19 and maternal and child food and nutrition insecurity: a complex syndemic. Matern Child Nutr. 2020;16(3):e13036.

26. Rajabiun S, Tryon J, Feaster M, Pan A, McKeithan L, Fortu K, et al. The influence of housing status on the HIV continuum of care: results from a multisite study of patient navigation models to build a medical home for people living with HIV experiencing homelessness. Am J Public Health. 2018;108(S7):S539-45.
27. Sachdev D, Mara E, Hsu L, Scheer S, Rutherford G, Enanoria W, et al. COVID-19 susceptibility and outcomes among people living with HIV in San Francisco. J Acquir Immune Defic Syndr. 2021;86(1):19-21.

28. Strathdee SA, Magis-Rodriguez C, Mays VM, Jimenez R, Patterson TL. The emerging HIV epidemic on the Mexico-U.S. border: an international case study characterizing the role of epidemiology in surveillance and response. Ann Epidemiol. 2012;22(6):426-38.

29. Pellowski JA, Kalichman SC, Matthews KA, Adler N. A pandemic of the poor: social disadvantage and the U.S. HIV epidemic. Am Psychol. 2013;68(4):197-209.

30. Brown MJ, Weissman SB. The impact of COVID-19 on older adults living with HIV: HIV care and psychosocial effects. j Gerontol Soc Work. 2020;63(6 7):602-6.

31. Joska JA, Andersen L, Rabie S, Marais A, Ndwandwa ES, Wilson P, et al. COVID-19: increased risk to the mental health and safety of women living with HIV in South Africa. AIDS Behav. 2020;24(10):2751-3.

32. turok I, Visagie, J. 2021 COVID-19 amplified urban inequalities. S Af J Sci. 117(3/4)

33. Gesesew HA, Mwanri L, Stephens JH, Woldemichael K, Ward P. COVID/HIV Co-infection: a syndemic perspective on what to ask and how to answer. Front Public Health. 2021;9:623468.

34. Logie $\mathrm{CH}$, Turan JM. How do we balance tensions between COVID-19 public health responses and stigma mitigation? Learning from HIV Research AIDS Behav. 2020;24(7):2003-6.

35. Ballester-Arnal R, Gil-Llario MD. The virus that changed Spain: impact of COVID-19 on people with HIV. AIDS Behav. 2020;24(8):2253-7.

36. Delle Donne V, Ciccarelli N, Massaroni V, Lombardi F, Lamonica $\mathrm{S}$, Borghetti A, et al. Psychological distress during the initial stage of the COVID-19 pandemic in an Italian population living with HIV: an online survey. Infez Med. 2021;29(1):54-64.

37. Dyer J, Wilson K, Badia J, Agot K, Neary J, Njuguna I, et al. The psychosocial effects of the COVID-19 pandemic on youth living with HIV in Western Kenya. AIDS Behav. 2021;25(1):68-72.

38. Weerasuria M, Ko C, Ehm A, O’Bryan J, McMahon J, Woolley I, et al. The impact of the COVID-19 pandemic on people living with HIV in Victoria. Australia AIDS Res Hum Retroviruses. 2021;37(4):322-8.

39. Marziali ME, Card KG, McLinden T, Closson K, Wang L, Trigg J, et al. Correlates of social isolation among people living with HIV in British Columbia. Canada AIDS Care. 2021;33(5):566-74.

40. Jones DL, Rodriguez VJ, Salazar AS, Montgomerie E, Raccamarich $\mathrm{PD}$, Uribe Starita $\mathrm{C}$, et al. Sex differences in the association between stress, loneliness, and COVID-19 burden among people with HIV in the United States. AIDS Res Hum Retroviruses. 2021;37(4):314-21.

41. Algarin AB, Varas-Rodriguez E, Valdivia C, Fennie KP, Larkey L, $\mathrm{Hu}$ N, et al. Symptoms, stress, and HIV-related care among older people living with HIV during the COVID-19 pandemic, Miami. Florida AIDS Behav. 2020;24(8):2236-8.

42. Qiao S, Yang X, Sun S, Li X, Mi T, Zhou Y, et al. Challenges to HIV service delivery and the impacts on patient care during COVID-19: perspective of HIV care providers in Guangxi. China AIDS Care. 2021;33(5):559-65.

43. SieweFodjo JN, Villela EFM, Van Hees S, Dos Santos TT, Vanholder P, Reyntiens P, et al. Impact of the COVID-19 pandemic on the medical follow-up and psychosocial well-being of people living with HIV: a cross-sectional survey. J Acquir Immune Defic Syndr. 2020;85(3):257-62.

44. SieweFodjo JN, de Moura Faria, Villela E, Van Hees S, Vanholder P, Reyntiens P, Colebunders R. Follow-up survey of the impact of COVID-19 on people living with HIV during the second semester of the pandemic. Int J Environ Res Public Health. 2021;18(9):4635. 
45. Pizzirusso M, Carrion-Park C, Clark US, Gonzalez J, Byrd D, Morgello S. Physical and mental health screening in a New York City HIV cohort during the COVID-19 Pandemic: a preliminary report. J Acquir Immune Defic Syndr. 2021;86(3):e54-60.

46. Diaz M, Cabrera, D., Gil-Zacarías, M., Ramírez, V., Saavedra, M., Cárcamo, C., Hsieh, E., García, P. . 2021 Knowledge and impact of COVID-19 on middle-aged and older people living with HIV in Lima, Peru. medRxiv preprint

47. Kumanan T, Rajasooriyar C, Guruparan M, Sreeharan N. The impact of COVID-19 on the delivery of critical health care: experience from a non-high-income country. Asia Pac J Public Health. 2020;32(8):473-5.

48. Gwadz M, Campos S, Freeman R, Cleland CM, Wilton L, Sherpa D, et al. Black and Latino Persons living with HIV Evidence risk and resilience in the context of COVID-19: a mixedmethods study of the early phase of the pandemic. AIDS Behav. 2021;25(5):1340-60.

49. Kalichman SC, Shkembi B, Kalichman MO, Eaton LA. Trust in health information sources and its associations with COVID-19 disruptions to social relationships and health services among people living with HIV. BMC Public Health. 2021;21(1):817.

50. Diaz-Martinez J, Tamargo JA, Delgado-Enciso I, Liu Q, Acuna $\mathrm{L}$, Laverde E, et al. Resilience, anxiety, stress, and substance use patterns during COVID-19 pandemic in the Miami adult studies on HIV (MASH) Cohort. AIDS Behav. 2021;25(11):3658-68.

51. Person B, Sy F, Holton K, Govert B, Liang A. National Center for Inectious Diseases SCOT. Fear and stigma: the epidemic within the SARS outbreak. Emerg Infect Dis. 2004;10(2):358-63.

52. Barrett R, Brown PJ. Stigma in the time of influenza: social and institutional responses to pandemic emergencies. J Infect Dis. 2008;197(Suppl 1):S34-7.

53. Des Jarlais DC, Galea S, Tracy M, Tross S, Vlahov D. Stigmatization of newly emerging infectious diseases: AIDS and SARS. Am J Public Health. 2006;96(3):561-7.

54. Berman M, Eaton LA, Watson RJ, Andrepont JL, Kalichman S. Social distancing to mitigate COVID-19 risks is associated with COVID-19 discriminatory attitudes among people living with HIV. Ann Behav Med. 2020;54(10):728-37.

55. Kalichman SC, El-Krab R, Shkembi B, Kalichman MO, Eaton LA. Prejudicial beliefs and COVID-19 disruptions among sexual minority men living with and not living with HIV in a high SARS-CoV-2 prevalence area. Transl Behav Med. 2021;11(7):1310-7.

56. Santos GM, Ackerman B, Rao A, Wallach S, Ayala G, Lamontage E, et al. Economic, mental health, HIV prevention and HIV treatment impacts of COVID-19 and the COVID-19 response on a global sample of cisgender gay men and other men who have sex with men. AIDS Behav. 2021;25(2):311-21.

57. Krier S, Bozich C, Pompa R, Friedman MR. Assessing HIV-related stigma in healthcare settings in the era of the COVID-19 pandemic, Pittsburgh. Pennsylvania AIDS Behav. 2020;24(9):2483-5.

58. Quinn KG, Walsh JL, John SA, Nyitray AG. "I feel almost as though I've lived this before": Insights from sexual and gender minority men on coping with COVID-19. AIDS Behav. 2021;25(1):1-8.

59. Ballivian J, Alcaide ML, Cecchini D, Jones DL, Abbamonte JM, Cassetti I. Impact of COVID-19-related stress and lockdown on mental health among people living with HIV in Argentina. J Acquir Immune Defic Syndr. 2020;85(4):475-82.

60. Jones DL, Ballivian J, Rodriguez VJ, Uribe C, Cecchini D, Salazar AS, et al. Mental health, coping, and social support among people living with HIV in the Americas: a comparative study between Argentina and the USA during the SARS-CoV-2 Pandemic. AIDS Behav. 2021;25(8):2391-9.
61. Tamargo JA, Martin HR, Diaz-Martinez J, Trepka MJ, DelgadoEnciso I, Johnson A, et al. COVID-19 testing and the impact of the pandemic on the Miami adult studies on HIV (MASH) Cohort. J Acquir Immune Defic Syndr. 2021;87(4):1016-23.

62. Cooley SA, Nelson B, Doyle J, Rosenow A, Ances BM. Collateral damage: impact of SARS-CoV-2 pandemic in people living with HIV. J Neurovirol. 2021;27(1):168-70.

63. Zvelebil MJ, Sternberg MJ, Cookson J, Coates AR. Predictions of linear T-cell and B-cell epitopes in proteins encoded by HIV-1, HIV-2 and SIVMAC and the conservation of these sites between strains. FEBS Lett. 1988;242(1):9-21.

64. Genberg BL, Astemborski J, Piggott DA, Woodson-Adu T, Kirk GD, Mehta SH. The health and social consequences during the initial period of the COVID-19 pandemic among current and former people who inject drugs: A rapid phone survey in Baltimore. Maryland Drug Alcohol Depend. 2021;221:108584.

65. Groves AK, Niccolai LM, Keene DE, Rosenberg A, Schlesinger P, Blankenship KM. Housing instability and HIV risk: expanding our understanding of the impact of eviction and other landlordrelated forced moves. AIDS Behav. 2021;25(6):1913-22.

66. Palar K, Frongillo EA, Escobar J, Sheira LA, Wilson TE, Adedimeji A, et al. Food insecurity, internalized stigma, and depressive symptoms among women living with HIV in the United States. AIDS Behav. 2018;22(12):3869-78.

67. McLinden T, Stover S, Hogg RS. HIV and food insecurity: a syndemic amid the COVID-19 pandemic. AIDS Behav. 2020;24(10):2766-9.

68. Sherbuk JE, Williams B, McManus KA, Dillingham R. Financial Food, and housing insecurity due to coronavirus disease 2019 Among At-Risk People With Human Immunodeficiency Virus in a Nonurban Ryan White HIV/AIDS Program Clinic. Open Forum Infect Dis. 2020;7(10):ofaa423.

69. Guaraldi G, Milic J, Martinez E, Kamarulzaman A, Mussini C, Waters L, et al. HIV care models during the COVID-19 era. Clin Infect Dis. 2020;19:ciaa1864.

70. Daniels JP. COVID-19 threatens HIV care continuity in Brazil. Lancet HIV. 2020;7(12):e804-5.

71. Hochstatter KR, Akhtar WZ, Dietz S, Pe-Romashko K, Gustafson DH, Shah DV, et al. Potential influences of the COVID-19 pandemic on drug use and HIV care among people living with HIV and substance use disorders: experience from a pilot mHealth intervention. AIDS Behav. 2021;25(2):354-9.

72. Ridgway JP, Lee A, Devlin S, Kerman J, Mayampurath A. Machine learning and clinical informatics for improving HIV Care continuum outcomes. Curr HIV/AIDS Rep. 2021;18(3):229-36.

73. Rao A, Rucinski K, Jarrett BA, Ackerman B, Wallach S, Marcus $\mathrm{J}$, et al. Perceived interruptions to HIV prevention and treatment services associated with COVID-19 for gay, bisexual, and other men who have sex with men in 20 countries. J Acquir Immune Defic Syndr. 2021;87(1):644-51.

74. Ristau J, Mehtani N, Gomez S, Nance M, Keller D, Surlyn C, et al. Successful implementation of managed alcohol programs in the San Francisco Bay Area during the COVID-19 crisis. Subst Abus. 2021;42(2):140-7.

75. Picchio CA, Valencia J, Doran J, Swan T, Pastor M, Martro E, et al. The impact of the COVID-19 pandemic on harm reduction services in Spain. Harm Reduct J. 2020;17(1):87.

76. Rogers BG, Arnold T, SchierberlScherr A, Strong SH, Holcomb R, Daley Ndoye C, et al. Adapting substance use treatment for HIV affected communities during COVID-19: comparisons between a sexually transmitted infections (STI) clinic and a local community based organization. AIDS Behav. 2020;24(11):2999-3002.

77. Zubiago J, Murphy M, Guardado R, Daudelin D, Patil D, Wurcel A. Increased HIV testing in people who use drugs hospitalized in the first wave of the COVID-19 pandemic. J Subst Abuse Treat. 2021;124:108266. 
78. Rozanova J, Shenoi S, Zaviryukha I, Zeziulin O, Kiriazova T, Rich K, et al. Social support is key to retention in care during Covid-19 pandemic among older people with HIV and substance use disorders in Ukraine. Subst Use Misuse. 2020;55(11):1902-4.

79. Closson K, Lee M, Gibbs A, Kaida A. When home is not a safe place: impacts of social distancing directives on women living with HIV. AIDS Behav. 2020;24(11):3017-9.

80. Wion RK, Miller WR. The Impact of COVID-19 on HIV selfmanagement, affective symptoms, and stress in people living with HIV in the United States. AIDS Behav. 2021;25(9):3034-44.

81. Friedman MR, Kempf MC, Benning L, Adimora AA, Aouizerat $\mathrm{B}$, Cohen MH, et al. Prevalence of COVID-19-related social disruptions and effects on psychosocial health in a mixed-serostatus cohort of men and women. J Acquir Immune Defic Syndr. 2021;88(5):426-38.

82. Dale SK, Pan Y, Gardner N, Saunders S, Wright IA, Nelson $\mathrm{CM}$, et al. Daily microaggressions and related distress among black women living with HIV during the onset of the COVID19 pandemic and Black Lives Matter Protests. AIDS Behav. 2021;27:1-8.

83. Hall A, Joseph O, Devlin S, Kerman J, Schmitt J, Ridgway JP, et al. That same stigma...that same hatred and negativity:" a qualitative study to understand stigma and medical mistrust experienced by people living with HIV diagnosed with COVID-19. BMC Infect Dis. 2021;21(1):1066.

84. Jones DL, Morgan KE, Martinez PC, Rodriguez VJ, Vazquez A, Raccamarich PD, et al. COVID-19 burden and risk among people with HIV. J Acquir Immune Defic Syndr. 2021;87(2):869-74.

85. Brouillette MJ, Koski L, Scott S, Austin-Keiller A, Fellows LK, Mayo NE. 2021 Factors influencing psychological distress during the COVID-19 pandemic in people aging with HIV. AIDS Res Hum Retroviruses
86. Folayan MO, Ibigbami O, Brown B, El Tantawi M, Uzochukwu B, Ezechi OC, et al. Differences in COVID-19 preventive behavior and food insecurity by HIV status in Nigeria. AIDS Behav. 2021;13:1-13.

87 Wagner GJ, Wagner Z, Gizaw M, Saya U, MacCarthy S, Mukasa $\mathrm{B}$, et al. Increased depression during COVID-19 lockdown associated with food insecurity and antiretroviral non-adherence among people living with HIV in Uganda. AIDS Behav. 2021;27:1-9.

88 West NS, Ddaaki W, Nakyanjo N, Isabirye D, Nakubulwa R, Nalugoda F, et al. A double stress": the mental health impacts of the COVID-19 pandemic among people living with HIV in Rakai. Uganda AIDS Behav. 2021;22:1-5.

89. Pantelic M, Martin K, Fitzpatrick C, Nixon E, Tweed M, Spice $\mathrm{W}$, et al. I have the strength to get through this using my past experiences with HIV": findings from a mixed-method survey of health outcomes, service accessibility, and psychosocial wellbeing among people living with HIV during the Covid-19 pandemic. AIDS Care. 2021;16:1-7.

90. Nitpolprasert C, Anand T, Phanuphak N, Reiss P, Ananworanich J, Peay HL. A qualitative study of the impact of coronavirus disease (COVID-19) on psychological and financial wellbeing and engagement in care among men who have sex with men living with HIV in Thailand. HIV Med. 2021.

Publisher's note Springer Nature remains neutral with regard to jurisdictional claims in published maps and institutional affiliations. 